\title{
Why Oyster Restoration Goals In The Chesapeake Bay Are Not And Probably Cannot Be Achieved
}

\author{
Roger L. Mann \\ Virginia Institute of Marine Science \\ Eric N. Powell \\ Rutgers University
}

Follow this and additional works at: https://scholarworks.wm.edu/vimsarticles

Part of the Marine Biology Commons

\section{Recommended Citation}

Mann, Roger L. and Powell, Eric N., "Why Oyster Restoration Goals In The Chesapeake Bay Are Not And Probably Cannot Be Achieved" (2007). VIMS Articles. 438.

https://scholarworks.wm.edu/vimsarticles/438

This Article is brought to you for free and open access by the Virginia Institute of Marine Science at W\&M ScholarWorks. It has been accepted for inclusion in VIMS Articles by an authorized administrator of W\&M ScholarWorks. For more information, please contact scholarworks@wm.edu. 


\title{
WHY OYSTER RESTORATION GOALS IN THE CHESAPEAKE BAY ARE NOT AND PROBABLY CANNOT BE ACHIEVED
}

\author{
ROGER MANN ${ }^{1 *}$ AND ERIC N. POWELL ${ }^{2}$ \\ ${ }^{1}$ Virginia Institute of Marine Science, Gloucester Point, Virginia 23062; ${ }^{2}$ Haskin Shellfish Research \\ Laboratory, Rutgers University, 6959 Miller Avenue, Port Norris, New Jersey 08349
}

\begin{abstract}
Efforts to restore the native oyster in the Chesapeake Bay enjoy enormous public support and have consumed and continue to consume vast, some would argue unreasonable and unjustifiable, amounts of funding. Despite this support the stated goals of restoration efforts are poorly defined and consequently provide no realistic measures of success in terms of time, space, or biomass. Quantitative approaches used successfully in management of and rebuilding plans for other marine and estuarine species have not been appropriately applied. Basic information in oyster population dynamics and ecology has been inadequately appreciated in defining the quantitative problem. Given these limitations it is not surprising that little success has been achieved despite the massive investment. We note a lack of ability to predict recruitment, and limit the ingress and impact of disease. Without control of both of these functions, populations cannot be managed in a self-sustaining rebuilding mode within the footprint that they either currently occupy or formerly occupied. Sustained expansion of that footprint through substrate provision is prohibitively expensive, beyond the limits set by availability of substrate material, and futile in the presence of disease and susceptible oysters. Without attaining a substantially increased and rebuilding population, ecological services will be limited. Water quality impacts will, in reality, be modest, local and seasonal, and still subject to being overwhelmed by periodic storm events. Coherent and rational evaluation of biological limitations will lead to more realistic, and indeed very modest goals for ecological restoration. We must accept the fact that efforts to date to restore native oyster populations have failed and the prognosis for improvement of this situation is continued failure. The argument is proffered that stabilizing the present bed footprint with a realistic and sustainable population and the promotion of aquaculture to increase commercial yield is a more predictable and stable economic investment. Each of these options is consistent with the most realistic ecological outcome and should take priority in future efforts.
\end{abstract}

KEY WORDS: Oyster, Crassostrea virginica, restoration, fisheries management, recruitment, mortality, shell budgets

\section{ECOLOGICAL AND FISHERY RESTORATION: DEFINITIONS}

What is oyster restoration? This varies with the desired end point. Ecological and fishery restoration are convenient end members to consider.

\section{Ecological Restoration}

Ecological restoration is the provision of ecological services by a self-sustaining population within a defined footprint. Ecological services comprise benthic-pelagic coupling and the physical provision of complex, three-dimensional habitat structure. The often-proffered attributes of oysters to improve "water quality" through filtration are subsumed within benthic-pelagic coupling. Ecological restoration includes as well the increase in habitat complexity and resultant enhanced species richness (e.g., Nocker et al. 2004, Tolley \& Volety 2005) and providing opportunity for higher-level predators (Harding \& Mann, 2001a, 2001b). Oysters have pelagic larvae with the capability of lateral dispersal. Thus apparently isolated populations, extant as reefs or the contiguous footprints of former reefs separated by regions devoid of either live oysters or

Footnote to the reader: This commentary is written to incite debate. Public trust has been vested in the scientific community to restore oyster to the Chesapeake Bay. We have spent vast amounts of money and to date demonstrated little progress. We offer the opinion that if this had been a private industry agricultural challenge, we would have either been fired long ago for not solving the problem or the challenge would have been redefined with pursuit of novel and tractable alternative options. We invite your response.

*Corresponding author. E-mail: rmann@vims.edu. characterized by sedimentary habitat unsuitable for oysters, can be connected as subunits of a larger population (metapopulation). It is tempting but erroneous to consider all oysters in the Chesapeake Bay as a single metapopulation with open recruitment from a limitless or undefined spatial region. Larval dispersal, as will be addressed later, is limited on a per generation time frame. Thus the metapopulation comprises exporting source populations and importing sink populations, likely differentially distributed from year to year imposing complex structural requirements for stability even in the short term (we appreciate the possibility of migration of source locations with changing environments over geological time frames but they are not relevant here). Metapopulations are severely spatially limited at this time by the end products of past harvest practices and the current disease pressure on unselected stocks (this is again a relative term that we revisit). Nevertheless ecological restoration, though often used in relevance to individual projects, connotes for most enthralled in the mystic of oyster restoration the re-establishment of the larger scale diffuse metapopulation with its many source and sink subunits.

\section{Fishery Restoration}

Fishery restoration is the provision of a sustainable economic resource. It does not require ecological restoration although it may contribute to it. It is possible to sustain an economic resource at less than maximum sustainable yield through careful management based on an understanding of recruitment and mortality rates - this is routinely accomplished with finfish during rebuilding plans. Both recruitment and mortality rates are difficult to estimate in oysters, rarely 
examined with adequacy in extant exploited populations, and afforded embarrassingly little attention in current "restoration" plans. Fishery restoration can be supported in its entirety on direct stock enhancement procedures such as hatchery seed production and deployment and shell planting and transplant of seed. Such exploited stocks, analogous to the Kansas wheat field, are ephemeral and may not by themselves supply desirable longterm ecological services because, by definition, they are destroyed at harvest. The more effective the harvest, the more complete the destruction. There are disease related reasons why complete harvest may be desired under some management scenarios and as this extreme is reached the dual option of exploitation and ecological restoration becomes less and less tenable. Rather, the dual role model is inconsistent with high fishery yield.

\section{BASICS OF RESTORATION: OUTLINE OF THE DEBATE}

Restoration is an exercise in resource rebuilding as practiced with any target fishery species. A failure to rebuild the resource negates any consideration of improved ecological services or enhanced water quality in addition to the provision of exploitable stocks. Balance in an exploited stock is a matter of simple mathematics. At equilibrium:

$$
\begin{aligned}
\mathrm{R}(\text { rate of recruitment })= & \mathrm{F}(\text { rate of fishing mortality }) \\
& +\mathrm{M} \text { (rate of natural mortality })
\end{aligned}
$$

These rates are expressed in the equation:

$$
\mathrm{dN} / \mathrm{dT}=(\mathrm{R}-\mathrm{F}-\mathrm{M}) \mathrm{N}
$$

and this equation is then normally implemented with the implicit goal that:

$$
\mathrm{dN} / \mathrm{dT} \geq 0 \text { or } \mathrm{R} \geq \mathrm{F}+\mathrm{M}
$$

But, with oysters the relationship is complicated in that oysters create their own habitat. Consider that most targeted fishery species' rebuilding plans are based on presumptions about the availability of essential fish habitat for that species and the option for rebuilding stocks to occupy available habitat. Rebuilding oyster populations is not simply an issue of increasing resident numbers of oysters; it is a parallel and equal issue of habitat. Both habitat and population size must be rebuilt and maintained in concert and in equilibrium or failure is assured.

The shell balance of an oyster reef has been expressed by Powell et al. (2006) as:

$$
\mathrm{dS} / \mathrm{dT}=(b-l) \mathrm{S}
$$

where $\mathrm{S}$ is the shell stock, $b\left(\right.$ time $\left.^{-1}\right)$ is the rate of shell addition and $l\left(\right.$ time $\left.^{-1}\right)$ is the rate of shell loss. For what is likely to be the vast bulk of oyster bottom, shell loss rates are high; shell has a half-life of 3 to 10 years in Delaware Bay. Thus shell stock is an unstable resource requiring persistent replenishment. Note that in any given year $b \mathrm{~S}$ in Eq. (4) relates to $\mathrm{mN}_{\mathrm{R}}$ from Eq. (2):

$$
\phi \mathrm{mN}=b \mathrm{~S}
$$

where $\phi$ is the parameter expressing the efficiency of conversion of shell produced by natural mortality $(\mathrm{mN})$ into shell stock $(b \mathrm{~S})$. Consequently Eqs (3) and (5) can be melded thus:

$$
\mathrm{dS} / \mathrm{dT}=\mathrm{rN}-l \mathrm{~S}-\mathrm{dN} / \mathrm{dT}=\phi \mathrm{mN}-l \mathrm{~S}
$$

Equation (6) shows that a dynamic exists between habitat, recruitment, shell loss, and natural mortality. Note the perver- sity of this relationship. To maintain habitat, oysters must die Ultimately, the status of habitat itself is dependent on the rate at which oysters recruit and die. We can think of the shell demand to rebuild habitat as a natural fishery in that the population is exploited to meet a demand. When the population is robust, the demand can be met with a low mortality rate. When the population is depauperate, a high mortality rate is required and habitat sustenance becomes absolutely dependent on a high recruitment rate, an outcome unlikely to be within the evolutionary ambit of the species.

If $\mathrm{R}$ (recruitment rate) is greater than the sum of $\mathrm{F}$ (fishing mortality rate) and $M$ (natural mortality rate) then rebuilding is occurring, providing that $\mathrm{S}$ (shell habitat) is also accreting $(b>l)$. Actions should therefore be assessed in terms of our understanding of their impact on rates of recruitment, fishing and mortality, and shell stock accretion. Arguably, the primary management and restoration goal, rather than specified by Eq. (3) as a focus of the living population, should be

$$
\mathrm{dS} / \mathrm{dT} \geq 0
$$

This requires a vibrant population. $\mathrm{F}$ can be managed and is therefore quantifiable. In the event of a fishery moratorium, a default situation in much of the Chesapeake Bay, $\mathrm{F}$ is zero and the debate simplifies to impacts on $\mathrm{R}, \mathrm{M}$ and $\mathrm{S}$ alone. For the sake of clarity we focus predominantly on rates of recruitment, mortality, and shell stock addition and loss in this text. Can we manipulate one or more of these successfully in such a way as to achieve the goal expressed by Eq. (2) without perpetual financial commitment?

Restoration of oysters to the Chesapeake Bay involves four major challenges. These are habitat degradation (reduction of shell coverage with accompanying reduction of opportunity for recruitment), the impacts of disease (direct increase in $\mathbf{M}$ with cascading impact on recruitment assuming a brood stockrecruit relationship and the premature transfer of shell to shell stock), low extant spawning stocks of oysters (impact on recruitment assuming a brood stock-recruit relationship), and infrequent, unpredictable recruitment (some environmental but as yet poorly understood and unmanaged impact on recruitment).

\section{IMPORTANT BASICS OF OYSTER BIOLOGY}

Prior to discussion of Eqs. 1 and 2 and the options for their manipulation, it is relevant to review elements of oyster biology and the local context of the Chesapeake Bay environment.

\section{The Oyster}

The lineage of oysters is ancient: the Chesapeake Bay is very young and ephemeral feature. Oysters of the genus Crassostrea have a fossil lineage of approximately 60 million years. Their adoption of a monomyarian (one adductor muscle) form and the discarding of the foot as a mechanism of adult movement dictate their reef forming habit in temperate and subtropical estuaries and coastal environments. Reefs are not optional to oyster perpetuation over geological time, they are essential. Estuaries are ephemeral over geological time, they come and go on a geological time frame of thousands to hundreds of thousands of years with changes in sea level. Over this geological 
time frame oysters invade estuarine environments as they form, occupy, and structure the communities in them during their geological interlude predominantly by the formation of habitat, and they suffer local extinction as sea level recedes. The oyster exists because the rate of shell accretion through recruitment, growth, and mortality exceeds by some small amount the rate of shell loss. Indeed, local extinction should be expected as conditions dictate the obverse and the consequence is the loss of the population and ultimately the habitat. Buried shells are well described, but the simple disappearance of shell bottom must also routinely occur. Expectations of human facilitated imposition of constancy on this trend over a societal time frame of years (much less decades or hundreds of years) are naive. Oyster beds come and go according to variations in the natural environment as they are influenced by the process of shell gain and loss and these processes can be substantial on decadal time frames (Powell et al. 2007, Powell \& Klinck 2007, Powell et al. 1995) and the goal of diverting, derailing or delaying this process likely cannot be fulfilled. Abetting the process is a wiser option.

The major elements of larval biology accommodate for the invasion of and retraction from local ephemeral environments, whereas maintaining a behavioral repertoire that has sustained the genus over tens of millions of years. The aggregative settlement behavior of oyster insures that newly settled forms are afforded physical refuge from predation and stress during early postsettlement growth to predator refuge size (Grabowski $\&$ Powers 2004). Aggregative settlement also insures close proximity of adults when spawning occurs. Protandry and recruitment of young oysters minimizes the Allee effect that burdens other bivalves (Kraeuter et al. 2003) and is a critical adaptation permitting the successful creation and maintenance of reef habitat and reef populations.

The development and maintenance of reef structures was and is facilitated by transport of larval stages. The free swimming, planktotrophic larval stage has long been misinterpreted as a mechanism for sustained long-distance dispersal on the order of tens of kilometers based on simplistic approaches using the product of mean flow rate and average larval duration. Subsumed in this flawed logic is the assumption of open and effectively continuous recruitment over extended footprints. The planktotrophic larval form evolved primarily to exploit planktonic food; dispersal is a secondary trait (Strathmann 1985, 2007, McNamara 1994, Wray 1995, Havenhand 1995, Hickman 1999). Selection for long-distance dispersal is arguably limited to teleplanic larvae (sensu Scheltema 1986), a trait unsupported in larval oysters. A rational examination of typical rates of lateral larval dispersal can be equated to that required to sustain an invasion of new habitat concomitant with sea level rise, this is an experiment that has been successfully prosecuted by oyster over the past 60 million years. Such translation requires lateral rates of dispersal of tens to hundreds of meters per generation (Mann 2005). What is interesting is the accommodation of local recruitment hypothesis by oyster larval and population dynamics modeling (Dekshenieks et al. 2000, 1996, Klinck et al. 2002). The local recruitment hypothesis has substantial implications for maintenance of population foci within the metapopulation and imposes a constraint on the ambit of management options and restoration goals. It is very likely that local recruitment is influenced as much by the vagaries of inefficient larval dispersal and insufficient optimal substrate for settlement as inadequate brood stock. In fact broodstock insufficiency is very likely the least important of the triumvirate.

Oysters evolved a life history strategy in which individuals are long-lived. Among the many selective advantages of long life is the fact that the death of large, old individuals adds disproportionately to the shell resource on which the population depends and must, through death, maintain. Long life has profound implications on the role of dispersing larvae in recruitment, especially when the extant source and sink populations have truncated age distributions. Within the spatial limits of a metapopulation, larval dispersal may be invoked in maintaining connectivity between sources and sinks in spatially separated elements and thus contribute to population stability over time, but this is not required on an annual basis in longlived species. In fact recruitment varies profoundly from year to year and over multiyear spans (Austin et al. 1996, HSRL 2006) and this will imbue a tendency for shell volume to vary over multiyear time scales (Powell et al. 2006, Powell \& Klinck 2007) with the only stabilizing element being the maintenance of a substantial shell stockpile in the form of long-lived living animals moderating the amplitude of shell volume changes from that otherwise expected from the amplitude of varying recruitment.

The influence of generation time on spawning, recruitment, and habitat maintenance is poorly understood but singularly critical. Consider the scenario for long-lived oysters with progressive truncation of the year-class structure through fishing or disease. When oysters lived for a long time, each female spawned many times. Oysters are often considered as a prime example of protandrous hermaphrodites, and the ratio of males to female's changes profoundly with age (Guo et al. 1998, Kennedy 1983). An animal that changes from a male to a female can, at the change, be considered both a senescent male and a maturing female. So, the generation time of males has changed little over historical time, but the generation time of females has decreased markedly. It is noteworthy that species most susceptible to population collapse are those in which the females, by being larger in size, are more susceptible to mortality biased towards large size. Fishing is the quotidian instrument of collapse but disease will also suffice. Thus, given that the effect of extant diseases, as we will discuss later, is to truncate age class structure, the subtle but possibly overwhelming effect is to reduce total female fecundity by limiting lifespan and the number of reproductive events per female. If the diseases have proportionately much less influence on the males, the only moderating action on this trend would be a real and substantial change in the male: female ratio. A thorough time series investigation of sex ratios over the period of disease impacts is absent to evaluate this possibility, but consider also the influence of reduced generation time on habitat. Records are at most suggestive (e.g., Moore 1907; 1911, Lunz 1938, Rothschild et al. 1994) but it is very likely that, at one time, a substantial surface layer and significant proportion of the total shell volume was locked up in living animals on oyster reefs. As generation time declined, the proportion of dead shell increased; the impact of the processes of shell destruction commensurately rose; and the sensitivity of habitat to periods of low recruitment increased. Although we cannot yet answer it, the question should be raised: can habitat stability be achieved naturally over decadal time periods in oyster populations with reduced generation times? 


\section{The Chesapeake Bay}

The Chesapeake Bay is an ephemeral geological feature. It is approximately 10,000 y old and exists as a drowned river valley filled by rising sea level over that period. Oyster reefs were formed initially by invasion of the new estuary by larval forms and aggregated settlement. Over time and many generations reefs emerged as significant biological features supporting extensive food webs and geological features reflecting cumulative settlement patterns in response to local hydrography. Both fringing (shoreline) and midstream reefs formed important elements of a mosaic that dominated the spatial physical structure of the bay and its subestuaries. These reefs moved over geological time in keeping with the demands of sea level rise and changing salinity regimen. It was not until the arrival of colonial settlement that the reversal of these millennia of habitat construction (shell accretion) were threatened by harvest (live oyster removal) and habitat destruction (shell loss) at levels over and above the subsistence harvesting of native peoples. The chronicles of the destruction of the Chesapeake oyster resource through direct harvest and the associated habitat are abundant, they do not warrant repetition here. The end point is the effective disappearance of three dimensional reef structures and their associated populations, both fringing and surrounded elements in the midstream portions, from the main-stem and subestuaries of the Chesapeake Bay.

\section{A VIGNETTE ON FISHING}

The influence of fishing on the equilibrium between the living population and the shell is subtle. If fishing mortality is an additive source of mortality then in any given year fishing does not influence shell addition; shell is produced by natural mortality and consequently the amount of shell produced would not change. In oyster populations with disease, some fraction of fishing mortality is compensatory (Klinck et al 2001) and this directly reduces shell input. Over longer time intervals, fishing reduces shell addition by removing animals that eventually would die and the total shell stock will decline from the pristine equilibrium. Consider the additive case as the easier to analyze. We should require, minimally, to manage such that $\mathrm{dS} / \mathrm{dT}=0$ and $\mathrm{dN} / \mathrm{dT}=0$. This is the constant abundanceconstant shell reference point and should be the absolute minimal acceptance standard for any fishery management program. Can this be achieved? In any single year the answer is yes. Over multiple years the answer is maybe. Without fishing, total mortality $(\mathrm{Z})$ equals natural mortality $(\mathrm{M})$ and from Eqs. (3) and (6),

$$
\mathrm{RN}=\mathrm{ZN}, l \mathrm{~S}=\mathrm{ZN}, \quad \text { and } \quad \mathrm{rN}=l \mathrm{~S}
$$

Shell produced through recruitment to the living population must equal shell loss through taphonomy. No fishing can exist for fishing would debit $\mathrm{ZN}$ and thus destabilize the equilibrium (Eq. 8). Fishing can only exist if simultaneously

$$
\mathrm{RN}>\mathrm{MN} \text { and } b \mathrm{~S}>l \mathrm{~S}
$$

That is, surplus production of the living population must exist as expressed by the left hand inequality. But also surplus shell production must exist as expressed by the right hand inequality.
Then, a fishing removal, FN or total allowable catch (TAC), exists such that

$$
\mathrm{FN} \leq b \mathrm{~S}-l \mathrm{~S} \text { and } \mathrm{FN} \leq \mathrm{RN}-\mathrm{MN}
$$

Management for habitat stability can only be successful if a desirable shellstock volume can be defined. This goal defines the necessary natural mortality rate to sustain the shell stock and this limits the fishery yield. In Delaware Bay the demands of shellstock outweigh the demands of the living population in fishery yield (HSRL, 2007). That is $\mathrm{dN} / \mathrm{dT}=0$ can be achieved under a higher $\mathrm{F}$ than $\mathrm{dS} / \mathrm{dT}=0$. So, the constraint imposed by Eq. (10) stipulates conditions where the reallocation of surplus production is necessary to assure sufficient natural mortality, thus debiting the allowable catch. The often-heard platitude that oysters should be caught before they die may describe precisely the wrong approach. These deaths may be essential to sustain the shell resource. Unlike nearly all other estuarine and coastal species, for oysters natural death is a desirable outcome because it sustains habitat on which the living population depends.

\section{ECOLOGICAL RESTORATION}

The mire of defeat in which we now reside issues from a failure to address the challenge of oyster restoration holistically. The holism expressed through Eq. (6) informs us of the interweaving of processes controlling recruitment, mortality and shell production, and shell loss. Success can come only with realistic goals couched within comprehensive and quantitative analysis delineating planned actions in concert within the complex interplay between population dynamics and habitat maintenance. Restoration programs have tended to focus on individual processes without the holistic foundation needed to express achievable goals. Some actions that we have taken offer hope and provide opportunity, but only when that foundation is laid. In what follows we discuss, under the rubric of the three basic components of Eq. (6), some of these approaches and consider how they devolve in their singular usage and how they might participate more productively in a more holistic framework. In the following examination of this objective, we recognize that one missing component is imposed on all restoration efforts. We cannot, or at least we do not know how to, vary $l$, the loss rate of shell. The following section will deal with the proposition that influence can be exerted on the remaining two controlling processes.

\section{Increasing Recruitment Rate, $R$, and Total Recruit $R N$, Through Habitat Management}

No restoration program can be successful without recruitment enhancement. Many processes conspire to limit recruitment and much of this conspiracy involves the interaction of disease and habitat degradation. The basic evolutionary adaptations of the oyster require long life, gregariousness and distributed population foci for metapopulation persistence. We know how to enhance recruitment in the short term. We fail (a) because we do not enclose these programs in a holistic framework and thus overstate expectations, (b) because we assume constancy in oyster distributions despite the lessons of geologic history that illustrate the ephemeral nature of specific distributional patterns, and (c) because we presume that such 
programs need only to be short term; that is we explicitly express an exit plan when even that last hundred years of experience should be sufficient to remind us that once begun, recruitment enhancement likely can never cease.

Manipulation of "habitat"-predominantly through the provision of substrate - to improve oyster (Ostrea, Crassostrea, and Saccostrea) recruitment is a world wide practice with at least a 2,000 y history that can be traced back to Roman times and the writings of Plini the Elder when he described the work of Sergius Orata spreading brush oak in Lake Avermis to encourage the settlement of the flat oyster Ostrea edulis. The Japanese record the settlement of oysters (Crassostrea species) on bamboo fish weirs in the 16th century and the French were deploying lime-coated tiles as oyster (O. edulis) spat collectors in Napoleonic times. Note that all of these activities used alternative (to oyster shell) substrates. Recent evaluations of such alternative substrates as compacted fly ash from power plant waste, shale, marl, shredded automobile tires, concrete waste from road construction, discarded porcelain bathroom fixtures, custom fabricated fish habitat, and water front retention structures fabricated variously from concrete, stone and/or other structural elements (e.g., LDWF 2004, Toline et al. 2005, Soniat et al. 1991) simply extend this 2,000-y tradition of provision of hard substrate to which oysters have had no exposure over evolutionary time, with perhaps the notable exception of mangrove oysters that recruit to exposed prop root systems of the red mangrove Rhizophora mangle (Bingham 1992), contribute to depositional processes that expand habitat for this pioneer mangrove (Myers \& Jewel 1990), and thereby facilitate their own perpetuation in a manner analogous to reef forming Crassostrea virginica.

The observation that settlement occurs on such hard substrates is neither unexpected nor novel. None of these substrates offer tractable alternatives to shell in large-scale application. Each suffers from one or more of the following negative attributes: lack of stability in flows (tires), compaction and fabrication costs, long-term stability and more economically attractive societal uses (fly ash, now used in roofing material), cost and availability in required gargantuan quantities in addition to undesirable permanence in the environment after deployment (all stone and concrete products), associated destruction of native waterfront and fringing environments (stone, concrete, wood, and "rip-rap" structures), and the wholesale adoption of a waste disposal attitude couched in an argument for environmental restoration (porcelain through concrete road and construction waste). In summary, the application of oyster shell, after 60 million years of proven environmental track record, must be the decision of choice. (We note, however, the opportunity of redirecting most shell generated by the offshore clam industry [surf clam and ocean quahog] as an additional shell resource and the urgent need for legislation requiring the disposal of such shell in an environmentally constructive manner, thereby facilitating its use in improving marine and estuarine environmental quality. The importance of shell in marine systems cannot be minimized [e.g., Meyer \& Townsend 2000, Kraeuter et al. 2003, Gutierrez et al. 2003, Guay \& Himelman, 2004])

Shell "planting" for oyster (C. virginica) enhancement (two dimensional application) was in progress in New York in the $1850 \mathrm{~s}$, and the mid-Atlantic bays followed before the end of the 1800 s. The focus of these efforts was exclusively for fishery enhancement with broad shell application in monolayers over extensive areas. Shell planting on the United States' east coast during the intervening decades has consumed literally millions of bushels of shell and hundreds of millions of dollars. The FY2006 federal budget earmarks for shell planting in New Jersey, Maryland, and Virginia alone exceeds 5 million US dollars with the states adding over $\$ 1$ million more to the bottom line. By contrast the building of three-dimensional habitat structures with the intent of restoring ecological services, rather than fishery enhancement, is a recent and comparatively minor effort. The necessity for substrate provision at all illustrates the impoverished status of oysters in the Chesapeake Bay and elsewhere. In an undisturbed situation natural oyster populations are keystone species in shallow water environments because of their ability to create habitat on which complex trophic webs are based. Even in a rebuilding mode there should be an aggregate accretion and accumulation of shell substrate. Yet nowhere is this observed in the Chesapeake or the Delaware Bays. Powell et al. (2006) note the half-life of shell resources in the Delaware Bay varies between 3 and $10 \mathrm{y}$. Even the most productive reefs in the James River do not demonstrate accumulation of shell substrate (Mann, Southworth, Harding \& Wesson, unpublished data). Surprisingly the "fate" of this disappearing shell is not well understood. The loss of substrate through burial and/or dissolution in sulfide rich sediments, and decline in substrate quality through actions of other organisms such as shell borers (various sponges, barnacles and even filamentous algae, see Pafford 1988) remain poorly quantified, yet their implication on the extraordinarily expensive practice of "habitat" management are obvious. (We note in passing that some shell types last longer than others [Gindy 1987, Staff et al. 1986, Callender et al. 1994]. They are resistant to the vicissitudes of taphonomy; but despite the many studies of the influence of substrate type on recruitment, we are unaware of a single study on the persistence of substrate types for habitat maintenance and multiyear recruitment enhancement. This would certainly seem to be a most fundamental oversight, especially for the preferred carbonate options: oyster, surf clam, ocean quahog, and the like.)

The dynamics of shell accumulation and loss are pivotal to management of oyster resources. As live oysters decline, the total available settlement space declines (both the live and the recently dead), but the rate of shell loss remains unchanged. One must emphasize the independence of the shell loss rate from the population dynamics processes in the living population. The instant total mortality declines so that the shell addition rate no longer balances or exceeds the shell loss rate; we begin a positive feedback loop that spirals downward. Perversely, a healthy oyster population requires both lots of oysters and lots of oysters that die. Diseases are helpful in the latter, but not in the former and only if recruitment rates remain high.

The implications of the formulation of Eq. (7) relating recruitment and mortality with the shell resource are intriguing. For example, how can we examine a brood stock-recruit curve when habitat (shell) may be limiting? Live oysters are a habitat bank, they store shell and then provide it through mortality to sustain habitat. They conflate the population dynamics with the shell resource through the expression specified by Eq. (5) relating natural mortality (M) to the rate of shell addition (b). Dead shells are habitat only, dead shells decay or are buried (loss rate function), and animals replenish the habitat part when they die but are lost from the stock estimate. Nowhere has this 
calculation been adequately evaluated. Adequate management of the shell resource requires that it be evaluated.

Shell planting, in the absence of adequate quantitative knowledge, and spending continues. It is a testament to the stubbornness of the management agencies and the political process, having adopted this practice many decades ago, that they support its perpetuation without critical evaluation of the inequality between natural shell addition and loss, the per year maintenance cost assuming average population dynamics, or even simple status quo on the reference points. It is a testament to the myopia of a scientific community that has by default endorsed the continued wasteful expenditure of public funds in the absence of fundamental quantitative information. For example, a revisiting of Eq. (6) relating recruitment, mortality and shell loss to shell coverage poses the question as to which elements have the greatest impact on shell? Is this declining recruitment or removal by fishing? Over-fishing causes lower abundance that precipitates an imbalance between recruitment and needed shell supply, but the singular problem is that shell loss $(l \mathrm{~S})$ is immune to regulation or any other form of control. Only by defining this imbalance can we define a restoration goal and provide a realistic estimation of the associated costs. Estimates of $\mathrm{R}$ and $\mathrm{M}$ are available from stock assessment surveys in both Delaware Bay by New Jersey scientists, and Virginia from collaborative surveys effected by the Virginia Marine Resources Commission (VMRC) and the Virginia Institute of Marine Science (VIMS), whereas $l$ can be calculated from the same databases (e.g., Powell et al. 2006). With estimates of $l$ we can assess maintenance and rebuilding costs assuming known losses to disease. We predict this will be a frightening calculation. Recent shell budget calculations for Delaware Bay (HSRL 2007), alas, support this prediction.

The only avenue to rebuild extant native populations is to insure recruitment and longevity of the recruiting individuals, the latter currently truncated by diseases as will be discussed later. Long-lived individuals in aggregated reefs provide, at their growth edges, a continual supply of new substrate unencumbered by competing fouling organisms and free of the degradation associated with shell borers; it is not by chance that the initiation of seasonal shell growth co-occurs with the season of settlement and metamorphosis and that such settlement enhances proximity of immobile spawning adults. In the absence of continued growth of a multiple year class population we can expect a reduction and eventual extirpation of available substrate. Our expectations are fulfilled by the current and past four decades of observations of extant populations and confirmed every time we create a new reef or deploy substrate, we watch the settlement trend decrease as the substrate eventually degrades and/or is occluded. In the long term continual substrate, planting may not be a tractable option to effect restoration-sustained recruitment at both frequencies and intensities higher, much higher than at present are required. The requirement for oysters to provide both a harvestable product and maintain their habitat suggests that their management cannot use a simple balance between recruitment, mortality and fishing rates because we predict that much of the mortality function will be devoted to providing the shell necessary to maintain shell stock, $\mathrm{S}$. This is not the case for most other long-lived bivalves where $\mathrm{S}$ is not a function in management. Who can say, today, what is really necessary through a multiyear program of shell planting, recruitment enhancement, and wise fishery management to achieve even our minimal goal of $\mathrm{dS} / \mathrm{dT}=0$ ? It would be nice to know! But certainly, before we invest valuable shell resources in the building of new reefs or the restoring of those silted over we should confirm a positive shell balance on those most productive ones extant or first use that resource to establish and maintain such a shell balance on them.

\section{Decreasing Natural Mortality, M, by Pursuit of Disease Tolerance and the Underlying Need for Selective Breeding}

A great deal could be achieved by increasing oyster generation time. An increased proportion of females and increased lifetime reproductive capacity cannot but improve recruitment. Further, shell stores would improve as more shell is sequestered within the living community. But generation time, for females certainly, is controlled by disease. Finally, shell mass increases dramatically with animal length (Powell \& Klinck 2007), thus the death of geriatric individuals contributes disproportionately to shell mass.

The impact on oyster populations of two diseases caused by the protozoan parasites Haplosporidium nelsoni (MSX) and Perkinsus marinus (Dermo) continues in higher salinities and warmer months. Molecular evidence presented by Burreson et al. (2000) strongly support the hypothesis that MSX is of Japanese origin and arrived on the United States' east coast with importation of infected Crassostrea gigas. The susceptibility of $C$. virginica to MSX is to be expected given that the oyster has not enjoyed a period of millions of years of coevolution to develop tolerance. The recent lack of MSX epizootics in Delaware Bay and the modest impacts compared with Dermo in long-term monitoring in the James River suggest the development of MSX tolerance in extant populations exposed to MSX for multiple generations. The future impact of MSX disease is very likely controlled by the efficiency of disease refuges protecting disease susceptible genotypes that continually contribute larvae to the metapopulations larval pool. Although Dermo has been observed in $C$. virginica populations for at least $50 \mathrm{y}$, its impacts have become the major causes of disease mortality in recent decades. The nature of both diseases is particularly vexing in that their impacts are manifested in older year classes, typically those that have attained some size refuge from predation. Dermo can destroy a multiyear class demographic that would otherwise be desired for optimal brood stock structure. Historical surveys suggest a preponderance of large old oysters in relatively unexploited populations in comparison with today. Large oysters are rarely seen in Chesapeake Bay, or indeed most other estuaries, even in regions rarely subjected to commercial harvest. Longterm records from the Chesapeake and Delaware Bays illustrate the coherence of high salinity and Dermo related mortality in susceptible populations. As an example, age-specific mortality rates exceeding $70 \%$ per year in low river flow years in the James River, VA have been recorded in the 1994 2005 period (Mann, Harding, Southworth \& Wesson, unpublished data). Indeed, this is why extant subtidal communities of any size are limited to low salinity sanctuaries in the upper subestuaries in the Chesapeake Bay, these being similarly limited in the upstream distribution by the impact of spring freshets. 
Disease alone is not the only limiting function in the observed distribution of oysters in Virginia. Subtidal oyster communities suffer continuous predation, a situation exacerbated in recent years as apex predators, such as sharks, have been removed with a relaxation of associated pressures on cownose rays (Rhinoptera bonasus) with cascading and locally catastrophic predation losses on oyster populations (in commercial and restoration projects). The general distribution of oysters from the Seaside of the Virginia Eastern Shore to the Gulf Coast illustrates the survival advantages of intertidal location. Despite the ravages of disease, populations of oysters are to be found intertidally in such high salinity locations as the Seaside of the Eastern Shore and Lynnhaven Bay. They are probably substrate limited and generally enjoy higher recruitment than in lower salinities (long-term data within the bay additionally illustrate a strong relationship between salinity and recruitment). Nonetheless their year-class structure is also probably heavily truncated by eventual losses to disease, so they do not accumulate and create substrate by accretion. It is important here to distinguish between year-class structure, where multiple year classes from regular recruitment provide a buffer against disease related losses of older animals, versus size class structure that may illustrate multiple recruitments events per year (not rare at high salinities) but not necessarily consistent interannual recruitment that fails as such a multiple year class buffer. Populations in high salinities with high densities probably exhibit fairly rapid turnover (not many old animals) and can provide ecological services commensurate with their density (benthic-pelagic coupling and processing of primary productivity) but the lack of broad size structure argues for differing ability to offer structural refuge. This remains poorly examined. Additionally, high turnover rate accompanied by limited size and age representation dictates a limited ability to sustain significant commercial exploitation.

Substantial restoration of Chesapeake Bay oyster population will not occur without increased tolerance to both MSX and Dermo because these diseases limit one or both of the spatial footprint for oysters in the bay (where recruitment is lower) or the age structure of the population (where recruitment is higher). For the past $40 \mathrm{y}$ several laboratories have participated in selective breeding programs for $C$. virginica with the specific intent of producing disease tolerant strains. In truth this domestication program has greatest obvious application in husbandry-aquaculture. This long-term effort has been exploited for widespread application in restoration. Only recently has selection considered traits other than disease tolerance that befits oysters for restoration purposes, the attribute of high fecundity being an example. In their early years selection programs were modest in scope; however, more recent efforts using hatchery driven, quantitative programs, based on widely adopted protocols from animal and plant husbandry, offer multiple strains for testing and application in ecological restoration and aquaculture. Breeding programs are intensive, multiyear commitments that involve not only practical, iterative field-testing but also a parallel program of quantitative genetics to identify traits or markers associated with heritable traits. To date survival rates approaching 70\% per year (S. K. Allen Jr., VIMS, pers. com. 2006) in the face of intense disease challenge have been observed in the best performing stocks. Whereas such pro- gress is admirable compared with age specific mortality of $70 \%$ in unselected (see earlier note on MSX tolerance) James River stock, increased tolerance is an absolute prerequisite to re-establishment of a multiple year-class structure commensurate with rebuilding goals (see next section). Even in the presence of disease tolerance we have inadequate estimates of the time (years, perhaps decades) required for the genotype of the population as a whole to be changed enough to increase disease tolerance. This has happened once only in an extant population in recent time - the observed impacts of epizootics MSX in Delaware Bay in 1985-1986 and subsequent complete demise of that disease. In two years MSX susceptible oysters were, for all practical purposes, eliminated from this population. This provides some hope that bay genotypes can be manipulated.

\section{Population Biology, Increasing Stock Size (by reducing $M$ ) and increasing $R$, recruitment}

The propensity to use, at great expense, implantation of disease resistant stock in restoration efforts without understanding the dynamics of metapopulation structure risks adopting an approach with potential for failure. Just how often do oysters in any one location become the source of the next generation? What is the source to sink ratio in this metapopulation? Even in the presence of improved and sustained habitat, and disease tolerant oysters, there remains the simple fact that more oysters are required in targeted systems to facilitate restoration, especially in the lower salinities of the subestuaries of the bay (notably those in Maryland) where recruitment is sporadic (at best, in some instances it is absent for the majority of the time), and single year classes can dominate population structure for many years. Brood stock-recruit relationships are fundamental to rebuilding plans, and have been used successfully in finfish rebuilding programs on a worldwide basis, although an excellent example exists in the Chesapeake Bay in striped bass (Morone saxatilis) rebuilding. Quantitative oyster stock assessment in the Virginia subestuaries is beginning to provide data on the brood stock-recruit relationship (a simplistic approach that inadequately addresses $\mathrm{S}$ as described earlier) at subestuary levels and underscore the massive infusions of oysters that will be required to influence change, infusions that are orders of magnitude higher than have been generally achieved in prior, individual reef-based restoration efforts. Estimates of required additions vary from literally millions of spawning adults in small subestuaries to tens of millions in larger estuaries, often equivalent to doubling or larger of the extant standing stocks!

Two limitations exist. First, oysters do not recruit well in most years. Second, most oysters do not successfully leave progeny behind when they die. Massive infusions of brood stock oysters, even disease tolerant brood stock oysters, may not guarantee predictable populations increases over time. Long-term population analysis from both the Delaware Bay (HSRL 2006) and the Virginia sub estuaries, notably the James River (Mann, Harding, Southworth, Wesson, unpublished data) both illustrate that recruitment in resident oyster populations typically demonstrates annual replacement ratios (\#recruits: \# brood stock) in the range 0.3-0.5. To the best of our knowledge these are the only estimates of this simple ratio available for any extant exploited oyster population, yet its 
value in the management process is enormous. Given that median life expectancies of recruits are $<1$ (considering early life history predation losses) or approximately 3 y for $1+$ year classes (based on year class structure developed from length demographics and age versus length curves from growth studies) the observed replacement ratios of 0.3-0.5 represent an equilibrium population at best. Times of population expansion are few (a replacement ratio $\geq 1.0$ has been achieved in only 17 of 53 y in Delaware Bay); times of population contraction are many. It is the atypical years when replacement ratios exceed 1.0 that produce strong year classes that sustain both the resource and the fishery until a subsequent high recruit event (replacement ratios $>1.0$ ) recurs.

Such temporal recruitment patterns should not be surprising to malacologists with a working knowledge of bivalves with a life expectancy of 10-20 y, arguably typical in pristine oyster populations prior to human impacts on their habitats. Descriptions of strong year class structures exist for both scallops (Placopecten magellanicus) and surf clams (Spisula solidissima) in a series of stock assessment surveys completed by the Northeast Fisheries Center of the National Marine Fisheries Service in support of management plans developed by the Mid Atlantic Fisheries Management Council, (see also Serchuk et al. 1979 for scallop data, Picariello 2006 for surf clam data) and large mytilids (e.g., Modiolus modiolus Anwar et al. 1990) with comparable life expectancies - and implications for what happens when such structures fail, witness the loss of biological refuges from predators (Witman 1985) and the tenuous situation of populations of Modiolus modiolus in Strangford Lough in Northern Ireland (Roberts et al. 2004). In brood stockrecruit plots three factors are evident: (1) a general ascending relationship between stock size and recruitment at relatively low abundance, (2) compensation at high abundance where over filtering limits production in a dense population (a situation rarely observed today), and (3) a limited suite of points where atypically high recruit values are observed for the corresponding stock size. The latter are replacement ratios of $>1.0$ that are disproportionately influential in determining long-term population trends - they notably do not appear to be related to changes in $\mathrm{S}$, nor are they obviously related to changes in $\mathrm{N}$, a point to which we will return. The challenge is to understand why such atypical events occur, what manipulations are required to replicate them, and assuming such manipulations are even tractable (they may well not be if driven by climatic or other very large scale events) to implement them on a frequent basis to provide an increasing population size - rebuilding.

Within the emerging understanding of this paradox lies a very significant challenge for restoration in Virginia. With the advent of three-dimensional reefs and surrounding shell plants in selected subestuaries, we have infrequently observed atypical recruitment events on new shell plants (replacement ratios in the 4-6:1 range based on standing stock estimates of $>1$ y classes) in the Piankatank and Great Wicomico Rivers (Mann, Southworth, Harding \& Wesson, unpublished data). These events have encouraged relocation of recruits from the shell plants to alternate sites for grow out and eventual harvest, with subsequent application of further shell on the shell plant sites. This is a short-term fishery focused action and can only be supported on an economic basis if the cost of shell planting and relocation can be sustained within the eventual value of the harvested product $^{1}$. Relocation of recently recruited stocks does; however, remove potential brood stock oysters that would drive the brood stock-recruit curve in the desired direction. The balance between these competing end points for the limited resource will remain unsatisfactory until disease tolerance is widespread.

Part of the interannual variability in recruitment unquestionably lies in our poor understanding of spatial dynamics in oyster populations. Metapopulation dynamics suggest that efforts to date have been successful in establishing individual sources that export larvae for limited periods (reefs supplemented with additional brood stock), but they have failed to develop (a) locally complex networks of sources and sinks that have sufficient inherent stability to maintain recruitment levels at all points in the restored subestuary, and (b) a network that is stable over time frames of many years. Again, if we cannot simultaneously restore both a critical biomass and a critical area of spatial complexity as a single unit, then it is mathematically improbable that stability of recruitment will occur over subsequent time.

As we pursue mathematical descriptions of complex spatial population structures we should recognize yet another challenge in brood stock-recruit relationships. The effective population number for oysters is about $10^{-5}$ of the population (D. Hedgecock 1994). In practical terms this means that on most occasions a very small proportion of the brood stock supplies the successful recruits. Under such conditions there is no reason to believe that the effective brood stock is associated with the largest abundances and one fishing event could remove all the effective brood stock for any particular year! Because we know nothing about spatial distribution of individuals contributing to the effective population, the management response has to insure that healthy oyster populations are scattered throughout the range of the animal in the system. Then maybe a few of them will successfully reproduce each year. The issue of effective population size, however, has certain interesting implications for management (Bilton et al. 2002). First, in most years sources are few and sinks are many. The source to sink ratio is low. Second, the likelihood that insular restoration efforts will effect bay-wide recruitment is no higher than the probability that the locale will be, by chance, a source over, say, a three-year period. Genetic evidence does not provide much hope for that probability. Third, the introduction of disease resistant genes, to have significant hope of success, must occur simultaneously in a host of distributed locales, including those where selective advantage is low. Fourth, the result reinforces observations of highly variable year-to-year recruitment success per spawning female and suggests that this aspect of oyster biology is not of recent (post disease or post exploitation) origin (e.g., Laporte \& Charlesworth. 2002, Frankham 1995). But, on the other hand, if the right conditions exist, a substantial genotype change can occur in a single generation. Arguably, this explains the Delaware Bay case in which a massive MSX epizootic coincident with a downbay source population and a substantial recruitment event may apparently have permanently relegated MSX to the long list of occasional and unimportant Delaware Bay oyster parasites.

\footnotetext{
${ }^{1}$ This is an important point. Oystermen in New Jersey contribute \$2 per bushel to sustain a stock improvement program. In 2006 this was approximately $5 \%$ of their gross earnings based on an estimate of $\$ 40$ per bushel ex-vessel return. Assuming that two bushels of marketable oysters yield one bushel of shell, $\$ 4$ covers the cost to the habitat of the fishery; it is approximately shell neutral.
} 


\section{A Focus on Shell Resources}

We have yet to formulate, in a single coherent plan with defined quantifiable goals, the overall restoration challenge and desired footprint of final restoration. Current estimates of restorable habitat are approximately 11,000 acres in Virginia (J. Wesson, VMRC, pers. com. based on continuing update of the Virginia Oyster Restoration Atlas of Berman et al. 2002) and approximately 30,000-35,000 acres in MD (P. Jones, MD Department of Natural Resources, pers. com. 2006). De novo shell planting to a basal two-dimensional status requires up to 10,000 bushels/acre at $\$ 2$ to $\$ 2.50 /$ bushel planted costs, or approximately $\$ 20,000$ to $\$ 25,000$ per acre. These are slightly higher costs than currently paid by the VMRC repletion program but the latter include essentially discount prices to the resource agency (shells are worth more as driveway material) and a planting regimen in the vicinity of the source material. Assuming (unrealistically) an unlimited supply of shell at current prices, de novo application to the projected total area would cost approximately one billion dollars. Maintenance application of shell at 1,000 bushels/acre every 10 years would require approximately $\$ 10$ million/year. Neither of these funding expectations is anywhere near plausible. And this may not be nearly sufficient. We do not yet have enough information to evaluate the shell requirement above that supplied through natural mortality by present day depressed abundance. Arguably, insufficient shell exists to maintain the acreage at present day level and to rebuild some semblance of the original acreage suggested by some is certainly overly optimistic. Baylor (1894) and Yates (1913) surveys of one century past defined oyster bars in a very inclusive manner in broad polygons that were useful in regulatory actions but included much habitat that was marginal at best for oysters. Even the option to use the more modest habitat estimates of Haven et al. (1981) and less attractive alternate substrates does not allow realistic expansion to include extra thousands of acres without expenditures of extraordinary amounts of money, an investment that should not be made in any event until we are sure that sufficient shell resources exist to sustain the footprint of the present day productive reefs!

Our expectations for three dimensional reef structures have not been fulfilled. Beginning in 1993, with the construction of an intertidal reef structure at Palace Bar in the Piankatank River, the Commonwealth of Virginia has, in partnership with various federal and nonprofit partners, embarked on an aggressive program of reef building as a seminal component of oyster habitat restoration. The rationale for reef construction was that provision of substrate would encourage oyster recruitment in high concentrations, that the initial absence of oysters would result in predominantly disease-free populations, that the vertical relief would facilitate oyster growth and survival, that resulting high densities of oysters would improve fertilization efficiency at spawning, that oyster populations would increase with subsequent generations throughout a positive feedback loop, and that robust, self sustaining populations would prevail to improve ecological services, provide complex habitat, and improve water quality. Recruitment to the Palace Bar reef was modest with population densities of $50-70$ oysters $\mathrm{m}^{-2}$, much less than that of extant population in self-sustaining populations in the James River (Mann \& Evans 1998). Endemic diseases became established threatening to minimize any advantage gained by recruitment to virgin reefs.
A modification in restoration strategy was adopted when the sanctuary reef constructed in the Great Wicomico River in June 1996 was provided with supplementary brood stock in December 1996. A remarkable recruitment event followed in 1997 (Southworth \& Mann 1998), encouraging an increase in the construction of sanctuary reefs. To date over 100 reefs have been constructed in Virginia, 59 of which are in the Chesapeake Bay. This has been an incremental process, often limited by funds and availability of shell resource, that, where possible, employs brood stock addition to the reef structures and strategic placement of extensive shell "plants" such that shell with recent recruits ("spat on shell") can subsequently be dredged and transferred to alternate locations for grow out and/or establishment of distant populations in other subestuaries. Brood stock oysters, where available, have come from state programs, through the admirable efforts of the Chesapeake Bay Foundation in concert with citizen and school groups, and they have increasingly used disease tolerant, selected lines of oysters. These efforts have, in harsh reality, met with varied and generally very little success. Initial increases in local recruitment generally suffer gradual declines over successive years in many locations. This may be attributed to lack of ability to adequately influence other major (quantitative) aspects of oyster population biology: the truncation of spawning stock structure (as mentioned earlier) to a few year classes by salinity related disease epizootics, the insurance of continued regular recruitment assisted by a strong stock-recruit relationship within populations, competition for substrate by other benthic organisms, and (again mentioned earlier) loss of substrate through burial and decline in substrate quality through actions of other organisms such as shell borers.

\section{So Where Do We Go From Here-What Options Are Available That Have Some Positive Contribution?}

The end point of this discourse is not complicated - restoration of native oysters to a rebuilding mode to provide ecological services is intractable in the absence of (a) disease tolerance in currently unselected or poorly selected extant populations, (b) multiple year class structure to buffer interannual recruitment variability, and (c) a population shell budget that is accretive in the absence of replenishment. Stated bluntly, restoration will not work under current conditions! In the absence of resurgence in bay wide stocks the often-flaunted goals of improving water quality must be radically revised. There is little question that the calculations of Newell (1988) estimating the ability of the oyster population of approximately $100 \mathrm{y}$ ago to filter the waters of the Chesapeake Bay in 3 days have completely captured the imagination of a swath of readers from ecologists researching benthic-pelagic coupling, to politicians seeking a "quick fix" for nutrient input reduction ("it's OK, more oysters will fix it"). These elegant calculations have limited practical context in current day application where the populations are severely depleted, have restricted generation times, recruitment levels and limiting options for rebuilding, and where the bay environment has been irretrievably changed by watershed and water body activities. Such filtration capability by extant oysters will never again be achieved. The degree of imbalance is well documented by Grall and Chauvaud (2002). Consider the following: The volume of the Chesapeake Bay is approximately $71.5 \times 10^{9} \mathrm{~m}^{3}$. Assume that $75 \%$ of this is in the main stem and unavailable for oyster filtration and that the impacts of any 
restoration will be in the remaining $25 \%$ of the volume in the subestuaries and the shallow regions (where, ironically the turbidity will be higher than the main stem disproportionately challenging filtration). A consideration of 45,000 acres of oyster habitat (the approximate restorable total in Virginia and Maryland combined) stocked with 100 adult oysters $\mathrm{m}^{-2}$, each of $1 \mathrm{gm}$ dry tissue weight (higher densities than the most productive reefs in the James River, and unquestionably higher than the vast majority of extant populations in the bay) filtering at summer rates (1-2 $\mathrm{L} \mathrm{hr}^{-1}$ based on Powell et al. 1992, Figure 1, low rate) produces an estimated ability to filter all the water in that $25 \%$ in approximately $14-28$ days. These filtration rates may be considered conservative. Using the rates in Newell et al. (2005), Table 2, which are based on the work of Jordan (1987) as used in the original calculations of Newell (1988) with summer maxima of $9.62 \mathrm{~L} \mathrm{hr}^{-1} \mathrm{~g}^{-1}$ dry weight decreases this value to 4.25 days. These are scenarios for optimal filtration at high population densities. Filtration decreases markedly with lower temperatures and realistic densities. Impacts on water quality will at best be modest, local, and seasonal. Similarly the target for a 10 -fold increase in biomass over a 10 -year period, so popularized in the media, has no rational basis in quantitative biology. The desire of state and federal agencies, arguably driven by these unrealistic goals, to lead on the pathway of restoration has resulted in a mix of planning, oversight, funding and impact assessment committees, and working groups functioning in an environment where development of ever more ambitious policy is easy; but admission of possible failure is not. A return to basics employing elements of fishery biology with proven track records is overdue, long overdue.

We return to the relationship of Eq. (7) relating recruitment and mortality to the dynamics of the shell resource. Sustainability, $\mathrm{dN} / \mathrm{dT} \geq$ and $\mathrm{dS} / \mathrm{dT} \geq 0$ in productive bay regions, may be achieved with careful management and adequate financing of shell planting to offset disease limited generation time. Should we retrench and focus on this goal? Traditional shell repletion programs have proven to be ineffective with habitat restoration as the goal. We fear that the one-time addition of shell alone (or any other substrate) cannot permanently increase recruitment to adequately balance shell loss even in the absence of fishing. Shell repletion programs should be terminated if their intent is restoration rather than maintenance. They can only be supported for fishery production if the costs can be borne by the harvested product. Sanctuary reef construction and brood stock addition have failed to produce any consistent positive results despite a decade of effort and many "replicate" attempts. We are chagrined and discomforted that we cannot but guess at the requirements to achieve stability of population structure and habitat simultaneously, even in the most productive regions of the populations. In fact we are at a loss to provide simultaneous quantitative estimates of surplus production and surplus shell production, to identify the productive areas unequivocally in nearly all cases. So what can we do? There are two parts to this answer, one addressing the fisheries dependent upon extant wild populations and one offering alternatives not employing extant populations.

\section{Exploiting Wild Populations}

Are there opportunities to manage and exploit extant wild populations given that the preceding arguments suggest there should be few, if any oysters remaining, let alone enough to support a fishery? In truth there is only one substantial selfsustaining oyster population in Chesapeake Bay and it supports the only self-sustaining fishery. It is in the Burwell Bay region of the James River and is unusual in that it demonstrates longevity (of the population, not the individuals) in the face of disease, environmental challenges and fishery exploitation. Delaware Bay is blessed with an equivalent region, the Bennies Sands to Ship John section of the Delaware Bay (HSRL 2006). The standing stock of the James River public oyster resource (Baylor 1894 survey, not leased bottom) has been the subject of annual quantitative surveys (absolute numbers and biomass per unit area, not numbers per bushel with no ability to estimate bushels per unit area) through a joint program between VMRC and VIMS since 1993. The system is self-sustaining because the salinity limits the spatial impact of disease, the circulation encourages larval retention, and, very importantly, harvests are low. In the James River the harvest is about $30-35,000$ bushels/yr in a standing stock of about 500,000-750,000 bushels, or about $4.6 \%$ to $6.0 \%$ of the standing stock harvested annually. In Delaware Bay the annual fisheries removal under a sustainable resource goal has been around 4\% (HSRL 2006). These percentage rates are remarkably low when compared with those for surf clams and sea scallops, both of which have comparable life spans yet support large, very productive, and arguably stable fisheries in the Mid Atlantic Bight. In fact the removal rate in the James River and Delaware Bay oyster fisheries bears greater resemblance to that of the offshore fishery for the ocean quahog (Arctica islandica), with a life span exceeding two hundred years! Note, however, than surf clams, scallops, and ocean quahogs do not have an analogous $\mathrm{S}$ functional requirement in their management plans. In the James River we have, serendipitously, adopted very restrictive oyster fishing limitations, including time limits and the use of hand tong that limit shell loss. In doing so we have preserved the system such that some hope of balancing shell loss with recruitment can be achieved through recruitment at high levels and sufficient mortality to balance shell loss (Mann, Southworth, Harding \& Wesson, unpublished data). In Delaware Bay, even with a sustainable resource, the shell resource is losing ground (Powell et al. 2006) because present abundances, though substantial in the short term, are simply too low to provide the shell necessary to balance the taphonomic loss; however, with continued very conservative management, now with an increasing knowledge base, we can hope to maintain these habitats, these stocks and these fisheries. Recognize that such limited hopes apply to the most productive bay regions. We cannot hope to make significant changes without markedly successful genetic manipulation. Expenditures that do not focus on these outcomes are truly wasted.

We recommend that management of the wild resource to sustain a fishery and protect present day ecological services include (1) limited fishing at scales $\leq 5 \%$ of the stock, (2) return at industry cost the shell removed by the fishery via a "shell tax" or equivalent, and (3) invest in shell maintenance to offset the debilitation of disease and encourage recruitment. Item (3) is a tax imposed to preserve the present day habitat integrity of the bay. If we are willing to accept the continued slow loss of shell resource, the first two will suffice. These first two remove the fishery as an agent of habitat decline. We further recommend that, until these two are simultaneously successfully accomplished, all efforts to expand the reef footprint cease. Adding acreage simply provides more 
exposure of shell to taphonomic processes and valuable shell necessary to sustain the present footprint is thereby irretrievably lost.

\section{AQUACULTURE AS AN ALTERNATIVE}

We must take bolder steps to embrace large-scale intensive aquaculture to sustain the industry. Every stable or expanding oyster industry, defined as a privately funded economic enterprise based on sale of end product, on a worldwide basis employs husbandry (aquaculture) to varying degrees. Such industries have developed and remain economically viable under similar constrictions of degraded environment, long-term fishing pressure with depleted stocks, and in several instances the presence of challenging diseases. The remaining options for the Chesapeake Bay oyster resource are all variants of husbandry and Delaware Bay has moved persistently in this direction over the past decade. These are based on economic rather than self-sustaining ecological deliverables. Of paramount importance is that they are predictable within increasingly well-defined bounds. They require survival only to a predetermined harvest size, make no prerequisite for multiple year-class presence or contribution to subsequent recruitment, and make no pretense of providing continuing ecological service, although the intermittent impact may be positive. Current work in Maryland employing planting of cultured oysters on "cleaned" natural bars (to remove resident oysters with any residual disease) in low salinity (fostering low disease pressure in any seed planting) with the intent of serving as long-term sanctuaries prior to serving a defined fishery at some later date fall into this category as intensive aquaculture. Downbay planting of shell in high recruitment areas and immediate upbay transplant (within two weeks of settlement) in Delaware Bay to nursery grounds and subsequently controlled harvest is another approach. In 2006, about $25 \%$ of the Delaware Bay wild recruitment came from this activity and direct shell planting on natural beds to sustain the shell resource and enhance abundance. Ecological services are intermittently provided by this effort but restricted by harvest as long as stock rebuilding is not the goal. The economic viability of this approach in large scale (hundreds to thousands of acres) has yet to be critically examined but the feasibility of this approach to simultaneously sustain the living resource $(\mathrm{dN} / \mathrm{dT} \geq 0)$ and the habitat $(\mathrm{dS} / \mathrm{dT} \geq$ $0)$ has been established. Other than the James River, there are effectively no locations in the Virginia subestuaries that are afforded sanctuary from diseases that are not also subject to catastrophic local losses to freshets. This, ultimately is the limitation. Interestingly, a true restoration effort to expand shell acreage in a highly productive region like this has rarely been tried (e.g., Powell et al. 1995) but, very likely, such an option might expand abundance and fishery yield. Rather than attempting to restore the old footprint of the bay why not help nature expand the footprint where expansion is naturally feasible by investing in maintaining the most productive areas of the bay?

Private industry efforts in Virginia and New Jersey with intensive culture of triploid native oysters in off-bottom cage enclosures of various designs demonstrate that marketable premium product can be consistently grown in $18 \mathrm{mo}$. The limits of this market have yet to be explored, but the economic viability of the effort is supported by both the stability of small scale "farmers" to date where careful protocols of husbandry have been followed, and the recent expansion of a limited number of private efforts to hundreds of enclosures, mechanize deployment and retrieval, and cumulative investments well into seven figures. Shellfish husbandry has been widely adopted as a socially appropriate economic development option in areas with a rich history in capture fisheries - the mussel culture programs in Maine and the Canadian Maritime Provinces being prime examples. The ecological impacts of intense mussel culture are under current examination (DFO 2006). We should aggressively pursue similar studies of oyster culture in the Chesapeake and Delaware Bays, not for the purpose of unnecessarily choking its expansion but for facilitating wide debate on its environmental impacts (good and bad) in the context of societal benefits, and for education of a public that will have to accommodate zoning of the shallow waters for dedicated aquaculture purposes.

\section{A FOOTNOTE ON NONNATIVE SPECIES OPTIONS}

Non-native oyster species have been discussed at length as candidate species for fishery enhancement and/or aquaculture on a global basis (Mann 1979) and in the Chesapeake Bay (Mann et al. 1991 for Crassostrea gigas and the massive current effort in support of an Environmental Impact Assessment for Crassostrea ariakensis). Despite intense examination, the prospect for confident prediction of a nonnative species' ability to survive and establish self-sustaining populations capable of providing ecological services and/or supporting a fishery remains modest at best. The history of establishment or failure to establish by oyster species in novel environments, especially Crassostrea virginica (compare its success in the waters of British Columbia compare with that of Crassostrea gigas, see Bourne 1979, Ruesink et al. 2005) demonstrate our poor understanding of the invasion process. We hypothesize that all introductions and subsequent establishment of oysters in novel environments, at least of the genera Ostrea, Crassostrea, and Saccostrea, are limited by the same relationship expressed by Eq. (6) to become established. We can find no data to allow critical examination of this hypothesis for any extant oyster population, native or introduced, anywhere in the world; but we are disturbed by the failure to investigate the longevity of shell produced by these arrivals. In the Chesapeake and Delaware Bays, without good shell survival, sufficient to produce reef accretion, the ultimate goal of species introduction to restore ecological services will fail, and we truly question why we should take so great a risk of introducing this species if we cannot assuredly respond in the affirmative to the question: Can this species supply adequate shell to expand the present footprint of oyster bottom in the bay?

\section{ACKNOWLEDGMENTS}

This is Contribution Number 2870 from the Virginia Institute of Marine Science.

\section{LITERATURE CITED}

Anwar, N. A., C. A. Richardson \& R. Seed. 1990. Age determination, growth rate and population structure of the horse mussel Modiolus modiolus. J. Mar. Biol. Assoc. UK. 70:441-457.
Austin, H. M., D. Evans \& D. S. Haven. 1996. A retrospective time series analysis of oyster, Crassostrea virginica, recruitment (19461993). J. Shellfish Res. 15:565-582. 
Baylor, J. B. 1894. Method of defining and locating natural oyster beds, rocks and shoals. Oyster Records (pamphlets, one for each Tidewater, Virginia county, that listed the precise boundaries of the Baylor Survey). Board of Fisheries of Virginia.

Berman, M., S. Killeen, R. Mann \& J. Wesson. 2002. Virginia Oyster Reef Restoration Map Atlas. Comprehensive Coastal Inventory, Center for Coastal Resources Management, VIMS .

Bilton, D. T., J. Paula \& J. D. D. Bishop. 2002. Dispersal, genetic differentiation and speciation in estuarine organisms. Estuaries, Coastal Shelf Sci. 55:937-952.

Bingham, B. L. 1992. Life histories in an Epifaunal Community: coupling of adult and larval processes. Ecology 73:2244-2259.

Bourne, N. 1979. Pacific oysters, Crassostrea gigas Thunberg, in British Columbia and the South Pacific Islands. In: R. Mann, editor. Exotic species in aquaculture. Cambridge, MA: The M.I.T. Press. pp. 3-53.

Burreson, E. M., N. A. Stokes \& C. S. Friedman. 2000. Increased virulence in an Introduced pathogen: Haplosporidium nelsoni (MSX) in the Eastern Oyster Crassostrea virginica. J. Aquat. Anim. Health $12: 1-8$.

Callender, W. R., E. N. Powell \& G. M. Staff. 1994. Taphonomic rates of molluscan shells placed in autochthonous assemblages on the Louisiana continental slope. Palaios 9:60-73.

DFO. 2006. Assessing habitat risks associated with bivalve aquaculture in the marine environment. DFO Can. Sci. Advis. Rep. 2006/005. Fisheries and oceans Canada, Ottowa. ISSN 1480-4913.

Dekshenieks, M. M., E. E. Hofmann, J. M. Klinck \& E. N. Powell. 1996. Modeling the vertical distribution of oyster larvae in response to environmental conditions. Mar. Ecol. Prog. Ser. 136:97-110.

Dekshenieks, M. M., E. E. Hofmann, J. M. Klinck \& E. N. Powell. 2000. Quantifying the effects of environmental change on an oyster population: a modeling study. Estuaries 23:593-610.

Frankham, R. 1995. Effective population size/adult population size ratios in wildlife: a review. Genet. Res. Carnb. 66:95-107.

Gindy, A. R. 1987. The relative diagenetic order of preservation of skeletal structures in fossil debris of a Miocene coquina near Salum, Egypt. N. Jb. Geol. Palaont. Mh. 1987:27-42.

Grabowski, J. H. \& S. P. Powers. 2004. Habitat complexity mitigates trophic transfer on oyster reefs. Mar. Ecol. Prog. Ser. 277:291-295.

Grall, J. \& L. Chauvaud. 2002. Marine eutrophication and benthos: the need for new approaches and concepts. Glob. Change Biol. 8:813-830.

Guay, M. \& J. H. Himelman. 2004. Would adding scallop shells (Chlamys islandica) to the sea bottom enhance recruitment of commercial species. J. Exp. Mar. Biol. Ecol. 312:299-317.

Guo, X., D. Hedgecock, W. K. Hershberger, K. Cooper \& S. K. Allen, Jr. 1998. Genetic determinants of protandric sex in the Pacific oyster, Crassostrea gigas Thunberg. Evolution Int. J. Org. Evolution 52:394-402.

Gutierrez, J. L., C. G. Jones, D. L. Strayer \& O. O. Iribarne. 2003. Mollusks as ecosystem engineers: The role of shell production in aquatic habitats. Oikos 101:79-90.

Harding, J. M. \& R. Mann. 2001a. Oyster reefs as fish habitat: opportunistic use of restored reefs by transient fishes. J. Shellfish Res. 20:951-959.

Harding, J. M. \& R. Mann. 2001b. Diet and habitat use by bluefish, Pomatomus saltatrix, in a Chesapeake Bay estuary. Environ. Biol. Fishes 60:401-409.

Haven, D. S., J. P. Whitcomb \& P. Kendall. 1981. The present and potential productivity of the Baylor Grounds in Virginia. Va. Inst Mar. Sci. Spec. Rep. Appl. Mar. Sci. Ocean. Eng. No. 243:1-154.

Havenhand, J.N. 1995. Evolutionary ecology of larval typeschapter 3. In: L. McEdward, editor. Ecology of marine invertebrate larvae. CRC Press, Boca Raton, FL. pp. 79-122.

Hedgecock, D. 1994. Does variability in reproductive success limit effective population sizes of marine organisms? In: A. R. Beaumont, editor. Genetics and evolution of aquatic organisms. London: Chapman \& Hall. pp. 122-134.
Hickman, C.S. 1999. Larvae in invertebrate development and evolution. In: The origin and evolution of larval forms. In: B. K. Hall \& M. H. Wake, editors. San Diego, CA: Academic Press. pp. 21-59.

HSRL. 2006. Report of the 2006 stock assessment workshop (7th SAW) for the New Jersey Delaware bay oyster beds. $62 \mathrm{pp}$.

HSRL. 2007. Report of the 2007 Stock Assessment Workshop (8th SAW) for the New Jersey Delaware bay oyster beds. $70 \mathrm{pp}$.

Jordan, S. J. 1987. Sedimentation and remineralization associated with biodeposition by the American oyster Crassostrea virginica (Gmelin). Doctoral dissertation. University of Maryland, College Park, MD. 200. pp.

Kennedy, V. S. 1983. Sex ratios in oysters, emphasizing Crassostrea virginica from Chesapeake Bay, Maryland. Veliger 25:329-338.

Klinck, J. M., E. E. Hofmann, E. N. Powell \& M. M. Dekshenieks. 2002. Impact of channelization on oyster production: a hydrodynamic-oyster model for Galveston Bay, Texas. Environ. Model. Assess. 7:273-289.

Klinck, J. M., E. N. Powell, J. N. Kraeuter, S. E. Ford \& K. A. AshtonAlcox. 2001. A fisheries model for managing the oyster fishery during times of disease. J. Shellfish Res. 20:977-989.

Kraeuter, J. N., M. J. Kennish, J. Dobarro, S. R. Fegley \& G. E. Flimlin, Jr. 2003. Rehabilitation of the northern quahog (hard clam) (Mercenaria mercenaria) habitat by shelling-11 years in Barnegat Bay, New Jersey. J. Shellfish Res. 22:61-67.

Kraeuter, J. N., S. Buckner \& E. N. Powell. 2005. A note on a spawnerrecruit relationship for a heavily exploited bivalve: the case of northern quahog (hard clams), Mercenaria mercenaria in Great South Bay New York. J. Shellfish Res. 24:1043-1052.

Laporte, V. \& B. Charlesworth. 2002. Effective population size and population subdivision in demographically structured populations. Genetics 162:501-519.

LDWF. 2004. Final report for Louisiana's oyster shell recovery pilot project. Louisiana Department of Wildlife and Fisheries, socioeconomics research and development section and marine fisheries division.

Lunz, G. R, Jr. 1938. Comparison between pre-colonial and present-day oysters. Science 87:367.

Mann, R. 1979. Exotic species in aquaculture. The M.I.T. Press, Cambridge, MA. 363 pp.

Mann, R. 2005. So how far do larvae disperse? Theoretical and time frame considerations. J. Shellfish Res. 24:665(abstract).

Mann, R., E. M. Burreson \& P. K. Baker. 1991. The decline of the Virginia oyster fishery in Chesapeake Bay: considerations for introduction of a non-endemic species, Crassostrea gigas (Thunberg). J. Shellfish Res. 10:379-388.

Mann, R. \& D. A. Evans. 1998. Estimation of oyster, Crassostrea virginica, standing stock, larval production and advective loss in relation to observed recruitment in the James River, Virginia. $J$. Shellfish Res. 17:239-254.

McNamara, K. J. 1994. Diversity of Cenozoic marsupiate echinoids as an environmental indicator. Lethaia 27:257-268.

Meyer, D. L. \& E. C. Townsend. 2000. Faunal utilization of created intertidal Eastern oyster (Crassostrea virginica) reefs in the southeastern United States. Estuaries 23:34-45.

Moore, H. F. 1907. Survey of oyster bottoms in Matagorda Bay, Texas. Bur. Fish Doc. 610:1-86.

Moore, H. F. 1911. Condition and extent of the natural oyster beds of Delaware. U.S. Bur. Fish. Doc. 745:1-29.

Myers, R. \& J. Jewel. 1990. Ecosystems of Florida. University of Florida Press, Gainesville, FL. 765 pp.

Newell, R. I. E. 1988. Ecological changes in Chesapeake Bay: are they the result of overharvesting the American oyster, Crassostrea virginica? In: M. P. Lynch \& E. C. Krome, editors. Understanding the estuary: advances in Chesapeake Bay research. Chesapeake Research Consortium, Publication 129 CBP/TRS 24/88, Gloucester Point, Virginia. pp. 536-546.

Newell, R. I. E., T. R. Fisher, R. R. Holyoke \& J. C. Cornwell. 2005 Influence of eastern oysters on nitrogen and phosphorus regeneration 
in Chesapeake Bay, USA. In: R. Dame \& S. Olenin, editors. The comparative roles of suspension feeders in ecosystems. Volume 47, NATO Series: IV - Earth and environmental sciences. Amsterdam, Netherlands: Springer. pp. 93-120.

Nocker, A., J. E. Lepo \& R. A. Snyder. 2004. Influence of an oyster reef on development of the microbial heterotrophic community of an estuarine biofilm. Appl. Environ. Microbiol. 7:6834-6845.

Pafford, E. 1988. Distribution and taxonomy of endolithic algae occurring in the shells of Crassostrea virginica in the lower James River, Virginia. M.A. thesis, College of William and Mary, Williamsburg, VA.

Picariello. A. 2006. Population ecology of the Atlantic surf clam Spisula solidissima in the Middle Atlantic Bight. M.S. thesis. College of William and Mary, Williamsburg, VA.

Powell, E. N. \& J. M. Klinck. 2007. Is oyster shell as sustainable resource? J. Shellfish Res. 26:181-194.

Powell, E. N., J. N. Kraeuter \& K. A. Ashton-Wilcox. 2006. How long does oyster shell last on an oyster reef? Estuar. Coast. Shelf. Sci. 69:531-542.

Powell, E. N., E. E. Hofmann, J. M. Klinck \& S. M. Ray. 1992. Modeling oyster populations. 1. A commentary on filtration rate. Is faster always better? J. Shellfish Res. 11:387-389.

Powell, E. N., J. Song, M. S. Ellis \& E. A. Wilson-Ormond. 1995. The status and long-term trends of oyster reefs in Galveston Bay, Texas. J. Shellfish Res. 14:439-457.

Roberts, D., C. Davies, A. Mitchell, H. Moore, B. Picton, A. Portig, J. Preston, M. Service, D. Smyth, D. Strong \& S. Vize. 2004. Strangford Lough ecological change investigation (SLECI) Report to the environment and heritage service by the Queen's University, Belfast. 7 pp.

Rothschild, B. J., J. S. Ault, P. Goulletquer \& M. Heral. 1994. Decline of the Chesapeake Bay oyster populations: a century of habitat destruction and overfishing. Mar. Ecol. Prog. Ser. 111:29-39.

Ruesink, J. L., H. S. Lenihan, A. C. Trimble, K. W. Heiman, F. Micheli, J. E. Byers \& M. C. Kay. 2005. Introduction of non-native oysters: ecosystem effects and restoration. Annu. Rev. Ecol. Evol. Syst. 36:643-689.
Scheltema, R. S. 1986. On dispersal and planktonic larvae of benthic invertebrates: an eclectic overview and summary of problems. Bull. Mar. Sci. 39:290-322.

Serchuk, F. M., P. W. Wood, J. A. Posgay \& B. E. Brown. 1979. Assessment and status of sea scallop (Placopecten magelanicus) populations off the northeast coast of the United States. Proc. Nat. Shellfish. Assoc. 69:161-191.

Soniat, T. M., B. C. Broadhurst \& E. L. Haywood. 1991. Alternatives to clam shell as cultch for oysters and the use of gypsum for the production of cultchless oysters. J. Shellfish Res. 10:405-410.

Southworth, M. \& R. Mann. 1998. Oyster Reef Brood stock Enhancement in the Great Wicomico River, Virginia. J. Shellfish Res. 17:1101-1114.

Staff, G. M., R. J. Stanton, Jr., E. N. Powell \& H. Cummins. 1986. Time-averaging, taphonomy and their impact on paleocommunity reconstruction: death assemblages in Texas bays. Geol. Soc. Am. Bull. 97:428-443.

Strathmann, R. R. 1985. Feeding and non-feeding larval development and life history evolution in marine invertebrates. Ann. Rev. Ecol. Syst. 16:339-361.

Strathmann, R. R. 2007. Hypotheses on the origins of marine larvae. Ann. Rev. Ecol. Systematics. 199:89-117.

Toline, C. A., P. Kenny \& D. Bushek. 2005. Cement-coated stakes enhance recruitment of damaged oyster reefs (South Carolina). Ecol. Rest. 23:277-278.

Tolley, S. G. \& A. K. Volety. 2005. The role of oysters in habitat use of oyster reefs by resident fishes and decapod crustaceans. J. Shellfish Res. 24:1007-1012.

Witman, J. D. 1985. Refuges, Biological Disturbance, and Rocky Subtidal Community Structure in New England. Ecol. Monogr. $55: 421-445$

Wray, G. A. 1995. Evolution of larvae and developmental modes. In: L. McEdward, editor. Ecology of marine invertebrate larvae. CRC Press, Boca Raton, FL. pp. 413-441.

Yates, C. C. 1913. Summary of oyster bars of Maryland 1906-1912. United States coast and geodetic survey. Washington, DC. 79 pp. plus charts. 